\title{
ANALISIS PENGGUNAAN SONKEIGO DALAM DORAMA FROM FIVE TO NINE
}

\author{
D.Y. Wulandari ${ }^{1}$, K. E. K. Adnyani ${ }^{2}$, N. N. Suartini ${ }^{3}$ \\ ${ }^{123}$ Jurusan Pendidikan Bahasa Jepang, Universitas Pendidikan Ganesha, Singaraja,Bali \\ e-mail: dwi.yuliadhit@gmail.com \\ krishna.adnyani@undiksha.ac.id nnsuartini@undiksha.ac.id
}

\begin{abstract}
Abstrak
Penelitian ini bertujuan untuk menganalisis penggunaan bentuk dan fungsi sonkeigodalam drama From Five to Nine. Pendekatan yang digunakan adalah pendekatan deskriptif kualitatif dengan metode pengumpulan data metode simak dan catat. Sumber data adalah doramaFrom Five to Nine.Metode analisis data adalah dengan teknik Milles dan Huberman (1994).Hasil penelitian menunjukkan bentuk verba khusus digunakan untukmemastikan keadaan yang berhubungan dengan mitra tutur.Sonkeigo bentuk o+verba masu+kudasai digunakan untuk berbicara dengan orang yang baru pertama kali bertemu dan mengekspresikan permintaan. Sonkeigo bentuk reru atau rareru digunakan untuk mengungkapkan topik pembicaraan dan perasaan ketidaknyamanan.Sonkeigo bentuk verba+verba irassharu, nasaru, kudasaru digunakan untuk mengungkapkan sindiran.Prefiks 0 dan go serta sufiks sama digunakan sebagai bentukpenghormatan.Secara keseluruhan fungsi sonkeigo yang digunakan dalam drama ini adalah sebagai penghormatan, menjaga jarak, menyatakan rasa kepedulian, sebagai sindiran, dan menyatakan status sosial.
\end{abstract}

Kata kunci : bentuk sonkeigo, drama, fungsi sonkeigo

要旨

本研究の目的は、ドラマ「九時から九時まで」に使用される尊敬語の形および機能を明らかにする。 研究では、記述的定性的が使うことである。データ収集は「五時から九時まで]から行う。ドラマデ 一タは、Miles\&Huberman(1994)の理論によって分析した。結果、「特定形」の使用は相手の状況に 関して確認するものである。「お十動詞ます十ください」は初対面の人に話しかける時および依頼表 現の使用する。「動詞〜れる」および「動詞〜られる」使用は不快感を表現すると話題のためのもの である。「動詞十いらっしやる、なさる、くださる」は皮肉として表す表現を使用する。「接頭辞

「おとご」および接尾辞「〜様」」は名誉として表す表現を使用する。このドラマで使われ ている尊敬語の機能は敬意として、関係を維持する、気遣うを表すこと、皮肉を表すこと、 そして状況ため使用された。

キーワード:尊敬語の形、ドラマ、尊敬語の機能

\section{Pendahuluan}

Kesopanan dalam berbahasa merupakan hal penting karena dapat menjaga hubungan sosial serta keramahan hubungan. Aspek dalam menerapkan prinsip kesopanan berbahasa yang harus diperhatikan yakni ragam bahasa, situasi percakapan, serta budaya yang berlaku dalam suatu masyarakat (Leech, 1989). Salah satu negara yang menjunjung tinggi budaya kesopanan adalah Jepang, khususnya dalam berkomunikasi. Kesopanan berkomunikasi dalam bahasa Jepang ditandai dengan penggunaan ragam bahasa hormat yang disebut keigo. Keigo sebagai salah satu ciri khas bahasa Jepang memiliki norma dalam penggunaannya, sehingga pembelajar bahasa Jepang mengalami kesulitan untuk memahami keigo. Dalam bahasa Indonesia tidak terdapat ragam bahasa yang sepadan dengan keigo.

Keigo dibagi menjadi tiga yakni sonkeigo (bahasa menghormati), kenjougo (bahasa merendahkan diri), teineigo (bahasa sopan). Sonkeigo digunakan saat berkomunikasi yang 
berhubungan dengan atasan sebagai orang yang lebih tua usianya, lebih tinggi jabatannya yang berhubungan lawan bicara termasuk (aktifitas dan segala suatu yang berkaitan dengannya). Kenjougo digunakan untuk menyatakan rasa hormat terhadap orang yang dibicarakan dengan merendahkan diri termasuk benda, aktivitas, dan segala sesuatu yang berkaitan dengannya. Teineigo adalah cara bertutur kata dengan sopan santun yang dipakai oleh pembicara dengan saling menghormati atau menghargai perasaan masing-masing Hirai (dalam Sudjianto dan Dahidi, 2009).

Dalam penggunaan keigo terdapat konsep yang disebut uchi-soto, yang secaraharfiah uchi berarti 'dalam' dan soto berarti 'luar'. Konsep uchi-soto merupakan suatu konsep interaksi sosial yang telah menjadi bagian dari kehidupan masyarakatJepang. Ketika berkomunikasi dengan keluarga sendiri orang Jepang tidakmenggunakan bentuk hormat meninggikan, kecuali kepada orang lain. Sehinggakomunikasi yang terjadi dibedakan antara uchi-soto Shibata (dalam Astami, 2010).

Selain itu dalam budaya Jepang terdapat kepercayaan tradisional yakni Shintoyang disebut sebagai kepercayaan yang mampu memengaruhi aktivitas sertapenggunaan bahasa di Jepang. Di antara berbagai pandangan agama dan budaya yangdimiliki, bagi sebagian besar orang Jepang, Shinto memiliki pengaruh terbesar padakomunikasi mereka sebagai inti dari budaya mental dan perilaku mereka dengankesederhanaannya Tsujimura (dalam Hara,2003). Shinto sangat terkait dengankehidupan orang Jepang sebagai sistem nilai esensial dan cara berpikir.

Sehingga dapat disimpulkan bahwa dari kesadaran akan konsep uchi-soto diinteraksi sosial orang Jepang dapat berimbas pada gaya bahasa yang digunakan.Apabila berbicara dengan orang yang dianggap sebagai uchi, akan cenderungmenggunakan bahasa futsuu go (ragam bahasa biasa) sedangkan saat berbicaradengan orang yang dianggap sebagai soto maka akan cenderung menggunakan keigountuk menghormati orang luar tersebut. Budaya konsep uchi-soto inilah yang menjadipermasalahan apakah keigo selalu digunakan pada saat berkomunikasi dengan soto no mono (orang luar). Selain itu adanya pengaruh shinto dalam cerminan perilakumasyarakat Jepang dalam berkomunikasi yang menjaga keharmonisan antar sesamadan lingkungan.

Penggunaan sonkeigo tidak hanya ditemukan dalam kehidupan sehari-hari.Penggunaan sonkeigo juga dapat ditemukan pada karya sastra sebagai refleksikehidupan masyarakat secara nyata. Karya sastra yang dimaksud adalah karya sastramodern berupa, film, anime, drama dan lain-lain. Hal tersebut dapat dibuktikandengan adanya pendapat bahwa dorama atau film merupakan cara suatu sikapdirepresentasikan (Kutha, 2009). Sebagai contoh adalah dorama From Five to Nineyang merupakan salah satu dorama Jepang yang dirilis tahun 2015. Karakter tokohutama serta situasi dalam drama ini memengaruhi penggunaan ragam bahasa yangdigunakan.

Dalam penelitian ini dorama From Five to Nine karena terdapat penggunaansonkeigo dalam berkomunikasi. Dorama ini menggunakan sonkeigo karena tokohutama adalah seorang biksu bernama Takane. Tokoh utama lain dalam drama iniyakni Junko yang merupakan seorang wanita yang berasal dari keluarga biasa yangmenggunakan sonkeigo. Walaupun dengan latar belakang kehidupan yang berbedaantara Takane dan Junko tetapi kedua tokoh tersebut menggunakan sonkeigo padasituasi tertentu. Takane yang merupakan biksu terbiasa menggunakan bahasa sopantermasuk sonkeigo. Sedangkan Junko berasal dari keluarga biasa yang jarangmenggunakan sonkeigo. Perbedaan latar belakang kehidupan kedua tokoh tersebutmembuat drama ini menarik untuk diteliti. Selain itu drama ini dibintangi oleh artis

ternama di Jepang yakni Satomi Ishihara. Satomi Ishihara pernah meraihpenghargaandari Television Drama Academy Award sebagai aktris terbaik dalamperannya di drama From Five to Nine. Berikut adalah contoh penggunaan sonkeigooleh Junko ketika berkomunikasi dengan Takane saat pertemuan pertama di kencan buta.

Junko:ちょっと宜しいですか。

(Chotto yoroshii desuka?).

Bisakah saya meminta waktu sebentar?

Takane : はい。 
(Hai).

lya.

(FFtN: Eps 1)

Pada tuturan tersebut terdapat penggunaan sonkeigo bentuk verba khususyakni yoroshii yang dalam futsukei (bentuk biasa) yakni ii.Sonkeigo digunakan olehJunko sebagai bentuk dari permintaan kepada Takane. Karena situasi mereka padasaat itu adalah baru pertama kali bertemu maka Junko menggunakan sonkeigo untukmenyatakan adanya jarak dalam hubungan mereka.

Adanya penelitian sejenis sebagai bentuk dari pentingnya penelitian sonkeigo pernah dilakukan oleh Rahman (2016) yang membahas tentang penggunaan sonkeigo dalam sebuah anime berdasarkan bentuk, fungsi, serta refleksi budaya dalam suatu anime. Penelitian terebut membahas tentang sonkeigo anime Classsrom Crisis yang dikaitkan dengan refleksi budaya Jepang tentang reigi (kesopanan) pada kehidupan masyarakat sedangkan dalam penelitian ini membahas tentang penggunaan sonkeigo berdasarkan situasi tutur yang terjadi sehingga memengaruhi penggunaaan sonkeigo dalam drama From Five to Nine.

\section{Metode}

Dalam penelitian ini pendekatan yang digunakan adalah pendekatan kualitatif, yakni dengan mendeskripsikan tuturan sonkeigo yang digunakan dalam drama From Five to Nine. Dalam penelitian ini akan dideskripsikan bentuk serta fungsi sonkeigo. Jenis penelitian yakni penelitian deskriptif yang bertujuan untuk menjabarkan tuturan sonkeigo secara terperinci sesuai data yang telah diperoleh. Metode yang digunakan untuk mengumpulkan data yakni dengan teknik simak dan teknik catat.Selanjutnya dalam menganalisis data digunakan teknik Dalam melakukan aktivitas analisis data digunakan teknik Miles dan Huberman yakni reduksi data, penyajian data, dan penarikan kesimpulan. Berikut adalah langkah-langkah analisis data yang akan dilakukan:

1. Reduksi Data

Data yang telah didapat akan direduksi yakni dengan memilah tuturan sonkeigo yang telah didapat setelah diklasifikasikan. Data yang diambil yakni tuturan data penting yang mampu mewakili data yang lain. Karena data yang didapat dalam drama From Five to Nine cukup banyak, maka data akan direduksi untuk mempermudah proses analisis data.

2. Penyajian Data

Langkah selanjutnya yakni data disajikan dalam bentuk uraian. Karena penelitian ini adalah penelitian kualitatif maka data yang berupa tuturan sonkeigo akan diuraikan dan dijelaskan secara naratif.

3. Penarikan Kesimpulan

Penarikan kesimpulan bersifat sementara dan akan berkembang. Dalam penelitian ini akan ditarik kesimpulan bagaimana bentuk serta fungsi sonkeigo dan faktor yang memengaruhi penggunaan sonkeigo dalam drama From Five to Nine.

Dalam menganalisis data digunakan kajian pragmatik, teori bentuk sonkeigo dan fungsi sonkeigo.Selain itu didukung juga dengan teori faktor yang memengaruhi penggunaan sonkeigo.

\section{Hasil dan Pembahasan}

Dalam drama From Five to Nine ini ditemukan penggunaan sonkeigoyakni 28 data. Tetapi data yang akan dianalisis yakni 20 data yang telah mewakili penjelasan tentang bentuk serta fungsi penggunaan sonkeigo dalam drama From Five to Nine.Dari keseluruhan jumlah data yakni sebanyak 28 data, ditemukan penggunaan bentuk verba khusus sonkeigo yakni 4 data.Bentuk o+verbamasu+kudasai ditemukan 12 data.Penggunaan bentuk verba $\sim$ reru atau rareru ditemukan 4 data. Penggunaan verba kudasaru setelah verba lain ditemukan 2 data. Penggunaan prefiks dan atau sufiks ditemukan 6 data.Fungsi yang digunakan dalam drama From Five to Nine adalah sebagai penghormatan, untuk menyatakan martabat, untuk menyatakan jarak, untuk menyatakan rasa kasih sayang, sebagai permohonan atau permintaan serta sebagai sindiran atau celaan. 
1. Fungsi Sonkeigo untuk Penghormatan

Fungsi penghormatan kebanyakan digunakan dalam bentuk prefiks dan atau sufiks pada verba maupun kata benda. Misalnya penggunaanprefiks o dan go, sufiks sama pada verba maupun kata benda.

Data 1

Junko：あなたのお祖母様本当にいらっしゃらないんですよね?

(Anata no obaasama hontouni irasshanain desuyo ne?).

Nenek anda benar tidak ada kan ya?

(Data: FFtN 4.2)

Situasi :

Ketika Junko, Momoe, dan Asa menginap di kuil tempat Takane tinggal, Junko memastikan dan bertanya pada Takane tentang keberadaan Hibari (nenek Takane). Junko yang memiliki perasaan takut terhadap Hibari merasa khawatir apabila diketahui menginap di kuil tersebut.

Analisis :

Data 1 merupakan penggunaan sonkeigo yang dituturkan oleh Junko terhadap Takane.Saat berada dikuil untuk menginap bersama rekan kerjanya (Momoe dan Asa), Junko memastikan keberadaan Hibari dan bertanya kepada Takane.Sonkeigo yang dituturkan oleh Junko dengan menggunakan prefik お/o/ dan sufiks 様/sama/ yang ditujukan pada Hibari sehingga dalam bentuksonkeigo menjadi お祖母様 /obaasama/yang memiliki arti 'nenek' . Penggunaan sufiks sama dalam hal ini sebagai penghormatan kepada keluarga Takane yang merupakan seorang biksu. Selain itu Junko menggunakan verba khusus dari いるyang dalam situasi ini untuk menyatakan keberadaan seseorang.Sehingga bentuk sonkeigo menjadi いらっしゃる /irassharu/.Dalam tuturan tersebut Junko mengatakan いらっしやらないんです/irassharanain desu/ yang memiliki arti'tidak ada'.

Berdasarkan situasi ujaran penggunaan verba khusus irassharu pada tuturan tersebut ditujukan saat membicarakan Hibari. Karena Takane merupakan biksu dan Junko sedang berada di kuil tempat Takane tinggal, maka digunakan sonkeigo untuk menghormati Hibari sebagai topik pembicaraan. Meski Junko tidak terbiasa menggunakan bahasa sopan, tetapi iacenderung menggunakan sonkeigo saat berkomunikasi dengan Takane dan segala hal yang berhubungan dengannya. Dalam hal ini Hibari dijadikan sebagai topik pembicaraan.

Jika dilihat dari faktor yang memengaruhi, penggunaan tuturan sonkeigo tersebut dikarenakan faktor usia Junko yang lebih muda dari Hibari. Sehingga penggunaan sonkeigo oleh Junko diklasifikasikan berfungsi sebagai perasaan hormat terhadap nenek Takane yang memiliki usia lebih tua. Hal tersebut sesuai dengan teori Hinata (dalam Sudjianto dan Dahidi, 2004) yang menjelaskan bahwa fungsi sonkeigo sebagai perasaan hormat terhadap mitra tutur atau orang yang dibicarakan yang memiliki posisi tinggi secara sosial.

\section{Fungsi Sonkeigo untuk Menyatakan Status}

Fungsi sonkeigo berdasarkan Shigeo (Sudjianto dan Dahidi 2004) pada dasarnya digunakan untuk menyatakan menghormati lawan bicara atau orang yang dijadikan topik pembicaraan.Tetapi sonkeigo juga dapat secara tepat dapat digunakan sebagai menyatakan pendidikan dan menyatakan status pembicaranya.

Data 8

Takane :少々お待ちください。

(Shoushou omachi kudasai).

Tolong tunggu sebentar.

(Data: FFtN10.1)

Situasi :

Junko dan Takane yang sedang bertengkar, dipertemukan oleh rekan kerjanya di sebuah museum.

Analisis : 
Data 8 merupakan penggunaan sonkeigoyang dituturkan oleh Takane terhadap Junko.Bentuk sonkeigo yang digunakan adalah pola o+verba bentuk masu+kudasai.Verba dalam tuturan tersebut yakni 待つ/matsu/ yang mememiliki arti 'menunggu' .Konjugasi dalam bentuk masu menjadi 'machimasu' .Sehingga tuturan sonkeigo menjadi お待ちくだい /omachi kudasai/ yang memiliki arti 'tolong tunggu' .

Jika dilihat berdasarkan situasi ujaran, Junko ingin melihat senyum Takane untuk terakhir kalinya.Takane terpaksa untuk menjauhi dan menahan rasa cintanya kepada Junko.Hal tersebut karena hubungan mereka tidak disetujui oleh nenek Takane.Perbedaan lingkungan didikan Junko yang berasal dari keluarga biasa menjadi alasan nenek Takane tidak menyetujui hubungan mereka. Tujuan Takane menuturkan hal tersebut adalah untuk meminta Junko menunggu hal yang tidak bisa ia lakukan saat itu, yakni tersenyum. Takane menggunakan sonkeigo bertujuan untuk membuat Junko mengerti bahwa ia tidak ingin membahas tentang perasaan cinta mereka.

Jika dilihat berdasarkan faktor yang memengaruhi, penggunaan sonkeigo dikarenakan faktor didikan yang dimiliki Takane.Hal tersebut berpengaruh pada bahasa yang digunakan saat berbicara dengan Junko walau dalam keadaan menahan perasaan cintanya, Takane tetap menggunakan sonkeigo.Penggunaan sonkeigo bertujuan agar Junko beranggapan bahwa Takane sudah tidak memiliki perasaan terhadap Junko. Takane bermaksud memperlihatkan bahwa iamengikuti keinginan neneknya dan menjaga status sosial sebagai keluarga biksu.

Sehingga dapat diklasifikasikan fungsi sonkeigo untuk menjaga status Takane sebagai seorang biksu. Walaupun dalam keadaan menahan perasaan cinta kepada Junko, Takane tetap menggunakan sonkeigo sebagai bentuk penjagaan nama baik. Hal ini sejalan dengan teori Hinata (dalam Sudjianto dan Dahidi, 2004) bahwa sonkeigo berfungsi sebagai menyatakan status penuturnya.

\section{Fungsi Sonkeigo untuk Menyatakan Jarak}

Sonkeigo berfungsi juga untuk menyatakan jarak penutur dan mitra tutur yang memiliki jarak psikologis (kejauhan, kedekatan/ solidaritas). Penutur dan mitra tutur yang baru pertama bertemu akan menggunakan sonkeigo sebagai penanda bahwa ada jarak psikologis dalam hubungan Shigeo (dalam Sudjianto dan Dahidi, 2004).

Data 9

Takane :どうぞお座りなってください。

(Douzo osuwari kudasai).

Silahkan duduk.

(Data: FFtN 1.4)

Situasi :

Ketika kencan buta Junko terkejut saat mengetahui pasangannya adalah Takane yaitu seorang biksu yang pernah ditemuinya dalam upacara pemakaman.Junko merasa ada kesalahan karena pasangannya adalah seorang biksu yakni Takane.

Analisis :

Data 9 merupakan penggunaan sonkeigo bentuk o+verba bentuk masu+kudasai pada verba 座る/suwaru/ yang memiliki arti 'duduk'. Pola dasar sonkeigo dalam tuturan tersebut awalnya yakni bentuk o+verba bentuk masu+ni narimasuおすわりになります/o suwari ni narimasu/. Tetapi karena untuk meminta maka ditambahkan bentuk te kudasai. Sehingga dalam bentuk sonkeigo menjadi お座りになってください/o suwari ni natte kudasai/.

Berdasarkan situasi ujaran, penggunaan sonkeigo oleh Takane ditujukan kepada Junko untuk duduk terlebih dahulu. Junko merasa terdapat kesalahpahaman sehingga ia bisa bertemu dengan Takane saat kencan buta. Jika dilihat dari faktor yang memengaruhi penggunaan sonkeigo dikarenakan adanya jarak sosial antara mereka. Hal tersebut karena Takane dan Junko baru bertemu sehingga digunakan bentuk sonkeigo untuk menghormati lawan bicara.Sehingga dapat diklasifikasikan penggunaan sonkeigo berfungsi untuk 
menyatakan jarak antara Takane dan Junko. Hal ini sejalan dengan teori Hinata (dalam Sudjianto dan Dahidi, 2004).

4. Fungsi Sonkeigo untuk Menyatakan Permohonan atau Permintaan

Sonkeigo dapat digunakan sebagai bentuk permintaan atau permohohan. Misalnya dengan menggunakan bentuk o+ verba bentuk masu + kudasai sebagai sonkeigo yang menyatakan bentuk permohonan secara sopan.

Data 18

Takane: お迎えに上がりました。

(Omukae ni agarimashita).

Saya menjemput anda.

Junko:もう お帰りください。

(Mou okaeri kudasai).

Sudah silahkan pulang.

( Data: FFtN 2.2)

Situasi :

Ketika perjalanan pulang Junko bertemu Takane di jalan dekat rumahnya.Takane bermaksud untuk menjemput dan mengantar Junko pulang.

Analisis:

Data 18 merupakan penggunaan sonkeigo dengan bentuk o+verba bentuk masu+kudasai pada verba帰る/kaeru/ yang memiliki arti 'pulang'. Konjugasi bentuk masu menjadi kaerimasu.Sehingga bentuk sonkeigo menjadi お帰りください/okaeri kudasai/ yang memiliki arti 'silahkan pulang'.Penggunaan sonkeigo ditujukan kepada Takane karena Junko merasa kesal diikuti dan dipaksa untuk tinggal dikuil bersama Takane.

Berdasarkan situasi ujaran, penggunaan sonkeigo bertujuan agar Takane mengerti bahwa Junko tidak tertarik dengannya dan kehidupan dikuil. Tetapi karena Takane sangat mencintai Junko ia tetap mencoba agar Junko setuju untuk tinggal dikuil selama seminggu melakukan pelatihan menjadi calon istri Takane. Hal tersebut adalah syarat dari Hibari agar mengetahui kepribadian Junko.

Jika dilihat berdasarkan faktor yang memengaruhi penggunaan sonkeigo, yakni karena Junko adalah wanita.Walau dalam keadaan kesal Junko tetap menggunakan sonkeigokarena wanita biasanya lebih halus dan sopan dalam bertutur.Sehingga berdasarkan tujuan, dan faktor yang memengaruhi diklasifikasikan fungsi sonkeigo sebagai bentuk dari menyatakan permintaan kepada Takane untuk segera pergi.Hal ini sejalan dengan teoribahwa sonkeigo dapat digunakan untuk menyatakan permintaan atau permohonan (Takahashi, 2016).

5. Fungsi Sonkeigo untuk Menyindir atau Mencela

Selain digunakan sebagai penghormatan, sonkeigo juga dapat digunakan sebagai bentuk untuk menyindir atau mencela suatu perbuatan seseorang. Hal ini dimaksudkan sebagai bentuk pragmatik dari sindiran atau celaan.

Data 19

Junko: あなたに何言われようと何を贈られるられるようと私の気持ち変わりません。

(Anata ni nani iware you to nani wo okurareruyou to watashi no kimochi ga kawarimasen).

Saya tidak akan mengubah perasaan saya tidak peduli apa yang dikatakan atau apa yang akan diberikan oleh anda.

Situasi :

Saat di tempat kerja Junko, Takane bermaksud untuk meminta maaf atas kesalahannya.Tetapi Junko yang masih merasa kesal memintanya untuk pergi.

Analisis :

Data 19 merupakan penggunaan sonkeigo bentuk rareru pada kata 贈る /okuru/ yang memiliki arti 'mengantar', sehingga tuturan dalam bentuk sonkeigo menjadi 贈られる 
/okurareru/.Penggunaan sonkeigo tersebut merupakan bentuk verba pasif yang pada umumnya digunakan untuk terlihat lebih sopan.

Berdasarkan situasi ujaran, tuturan sonkeigo oleh Junko ditujukan saat Takane mengantarkan makanan sebagai tanda permintaan maaf karena telah melakukan kesalahan.Junko yang merasa kesal memintanya untuk pergi. Tetapi dalam hal ini terdapat perasaan kesal karena menurut pengakuan Takane ia yang telah menyebabkan wawancara Junko menjadi gagal. Oleh karena itu Junko mengabaikan permintaan maaf dan segala tindakan Takane.Junko menggunakan sonkeigo dalam keadaan kesal untuk mencela perbuatan yang dilakukan oleh Takane.Selain itu karena tempat mereka berkomunikasi pada sat itu adalah ditempat kerja, maka Junko menggunakan sonkeigo.

Jika dilihat berdasarkan faktor yang memengaruhi penggunaan sonkeigo, meskipun Junko dalam keadaan kesal tetap menggukan sonkeigo karena ia adalah seorang wanita. Karena wanita biasanya menggunakan bahasa sopan karena lingkungan menuntut untuk wanita menggunakan bahasa sopan, dan susah memaklumi apabila wanita menggunakan bahasa kasar dalam berkomunikasi. Sehingga dapat disimpulkan bahwa penggunaan sonkeigo diklasifikasikan berfungsi sebagai menyindir perlakuan Takane.Hal ini sesuai dengan teori Shigeo (dalam Sudjianto dan Dahidi, 2004).

\section{Fungsi Sonkeigo untuk Menyatakan Kasih Sayang}

Sonkeigo juga berfungsi untuk menyatakan kasih sayang, yakni dengan bertutur halus pada mitra tutur Hinata (dalam Sudjianto dan Dahihi 2004). Misalnya penggunaan sonkeigo pada anak-anak yang menandakan rasa kasih sayang orang tua terhadap anaknya. Hal tersebut dimaksudkan untuk menunjukkan keramahan dan kelembutan terhadap anak-anak.

Data 15

Takane :ならば好きとおっしやってください。

(Naraba suki to osshattekudasai).

Tolong ucapkan jika anda menyukai saya.

Junko :いや。ほら。そういうのは大事なときに言うから。

(lya.Hora.Souiuno wa taijina toki ni iukara).

Tidak.Hei.Karena saya mengatakan hal seperti itu, saat itu penting.

(Data: FFtN 8.1)

Situasi :

Takane sedang memastikan perasaan Junko.Karena Junko sudah terlihat mulai menyukai Takane.Percakapan dilakukan dirumah Junko.Dengan tujuan tuturan untuk mengetahui perasaan Junko terhadap Takane.

Analisis:

Tuturan data 15 merupakan penggunaan sonkeigo dengan menggunakan verbaくださる/kudasaru/ sebagai bentuk permintaan, setelah verbaいう/iu/ yang memiliki arti 'berbicara'. Bentuk khusus sonkeigo dari verba iu adalah おっしゃる /ossharu/. Dalam hal ini verba ossharu digunakan Takane untuk menanyakan perasaan Junko terhadap Takane.Jika dilihat dari faktor yang memengaruhi penggunaan sonkeigo yakni dikarenakandidikan lingkungan yang dimiliki Takane. Untuk meminta pernyataan suka dari Junko, Takane menggunakan sonkeigo sebagai penanda bahwa ia memiliki lingkungan didikan yang terbiasa menggunakan bahasa sopan yakni sonkeigo.

Berdasarkan situasi, tujuan serta faktor yang memengaruhi penggunaan sonkeigo dalam tuturan ini, diklasifikasikan fungsi penggunaan sonkeigo sebagai bentuk menyatakan rasa kasih sayang.Karena ossharu digunakan Takane untuk menghormati perasaan yang dimiliki oleh Junko terhadapnya.Hal ini sesuai dengan teori Hinata (dalam Sudjianto dan Dahidi, 2004). 


\section{B. PEMBAHASAN}

Dari keseluruhan jumlah data yakni sebanyak 28 data, ditemukan penggunaan bentuk verba khusus sonkeigo yakni 4 data.Bentuk o+verbamasu+kudasai ditemukan 10 data.Penggunaan bentuk verba reru atau rareru ditemukan 3 data. Penggunaan verba kudasaru setelah verba lain ditemukan 1 data. Penggunaan prefiks dan atau sufiks ditemukan 10 data.Penggunaan sonkeigo bentuk o+verba masu+kudasai digunakan untuk berbicara dengan orang yang baru pertama kali bertemu.Penggunaan sonkeigo bentuk reru atau rareru digunakan untuk mengungkapkan topik pembicaraan.Penggunaan sonkeigo bentuk verba+verba irassharu, nasaru, kudasaru digunakan untuk mengungkapkan sindiran.Prefiks dan sufiks digunakan sebagai bentuk penghormatan.

Penggunaan sonkeigo dalam drama From Five to Nine berfungsi untuk menyatakan penghormatan, menyatakan jarak, menyatakan permohonan atau permintaan, menyatakan kasih sayang dan menyindir atau mencela.Sedangkan fungsi sonkeigo untuk menyatakan situasi formal tidak ditemukan dalam penelitian ini.Fungsi sonkeigo yang banyak digunakan adalah untuk menyatakan penghormatan dan untuk memohon atau meminta.Ditemukan juga dalam beberapa situasi penggunaan sonkeigo digunakan untuk memarahi dan tidak terdapat dalam teori, tetapi penulis mengklasifikasikannya kedalam bentuk sindiran atau celaan.

Penggunaan sonkeigo dalam drama From Five to Nine tidak hanya digunakan kepada lawan bicara tetapi ketika membicarakan topik lain yang berkaitan dengan lawan bicara. Selain itu penggunaan sonkeigo ditemukan untuk meninggikan subjek dan perilaku dalam drama ini. Sehingga berdasarkan hasil analisis dapat disimpulkan bahwa penggunaan sonkeigo dalam drama From Five to Nine tidak semua sama dengan teori bentuk sonkeigo yang dikemukakan oleh Takahashi (2016) dan teori fungsi sonkeigo yang dikemukakan oleh Shigeo (dalam Sudjianto dan Dahidi, 2004). Karena tidak semua bentuk dan fungsi sonkeigo yang dikemukakan terdapat dalam drama From Five to Nine.

\section{Simpulan dan Saran}

Penggunaan sonkeigo bentuk verba khusus yang ditemukan sebanyak 4 data.Bentuk o+verba+kudasai ditemukan sebanyak 12 data.Bentuk reru/rareru sebanyak 4 data. Bentuk verba irassharu, ossharu, kudasaru, dan nasaru setelah verba lain ditemukan sebanyak 2 data. Penggunaan sonkeigo bentuk prefiks dan atau sufiks ditemukan sebanyak 6 data.Penggunan sonkeigo bentuk verba khusus digunakan untuk menasehati mitra tutur.Penggunaan sonkeigo bentuk o+verba masu+kudasai digunakan untuk berbicara dengan orang yang baru pertama kali bertemu.Penggunaan sonkeigo bentuk verba reru atau rareru digunakan untuk mengungkapkan topik pembicaraan.Penggunaan sonkeigo bentuk verba+verba irassharu, nasaru, kudasaru digunakan untuk mengungkapkan sindiran.Fungsi sonkeigo dalam drama From Five to Nine yang ditemukan yakni sebagai menyatakan penghormatan, menyatakan jarak, menjaga martabat, menyatakan rasa kasih sayang, sebagai permintaan atau permohonan dan sebagai sindiran atau celaan. Sedangkan fungsi sonkeigo untuk menyatakan formalitas tidak ditemukan.Fungsi sonkeigo untuk menyatakan jarak sering digunakan pada episode awal karena pada episode awal situasi antara Takane dan Junko masih pertama bertemu.

Selain itu terdapat juga beberapa data yang menggunakan sonkeigo sebagai smenyatakan jarak kepada topik lain yang berkaitan dengan mitra tutur dalam drama ini. Sedangkan Fungsi sonkeigo sebagai menyatakan rasa kasih sayang dan sindiran atau celaan jarang digunakan dalam drama ini. sehingga di episode awal konsep uchisoto terlihat jelas. Selain itu penggunaan konsepuchi-soto muncul saat hubungan mereka mengalami permasalahan, sehingga mereka menjaga jarak satu sama lain. Dapat disimpulkan konsep uchi-soto dalam drama From Five to Nine bersifat statis dan tetap dipergunakan oleh Takane kepada Junko dan keluarganya. Sedangkan sonkeigo yang digunakan oleh Takane kepada keluarganya merupakan wujud dari ajaran Shinto yang menjaga keharmonisan dengan keluarga atau leluhur.

Sehingga dapat disimpulkan bahwa penggunaan sonkeigo dalam drama From Five to Nine lebih sering digunakan tokoh Takane.Hal tersebut karenaTakane tinggal dalam lingkungan kuil yang mengharuskan bicara dengan sopan.Sedangkan sonkeigo yang 
digunakan Junko cenderung sederhana dalam bentuk penggunaan prefik dan sufiks. Hal ini dikarenakan Junko merupakan keluarga biasa yang jarang menggunakan bahasa sopan baik dengan keluarga maupun rekan kerja.

B. Saran

Selama penelitian dilakukan disadari terdapat beberapa kekurangan sehingga dibuat saran untuk penelitian berikutnya yakni:

1. Untuk peneliti selanjutnya, jika hendak melakukan penelitian tentang sonkeigo perhatikan saat memilah data, karena kecenderungan data sonkeigo (meninggikan lawan bicara) serupa dengan bikago (pengindahan bahasa Jepang umumnya ditambahkan prefik o dan go pada suatu verba).

2. Pilihlah objek yang menarik untuk diteliti misalkan dengan menggunakan karya sastra agar pembaca dapat tertarik untuk mengetahui tentang sonkeigo.

3. Disarankan mengambil data melalui studi kasus dengan mengamati penggunaan sonkeigo pada bahasa tulis maupun bahasa lisan sehingga dapat melihat perkembangan penggunaan sonkeigo dalam kehidupan nyata.

\section{Daftar Pustaka}

Chaer, Abdul. 2004. Linguistik Umum. Jakarta : PT.Rineka Cipta.

Kutha, Nyoman. 2009. Stilistika Kajian Puitika Bahasa, Sastra dan Budaya. Yogyakarta: Pustaka Pelajar.

Leech, Goeffery. 1983. Principles of Pragmatics. United States of America: Longman Group Limeted.

Rahman, Yahya Arief. 2016. Sonkeigo dalam Anime Classroom Crisis. Tesis (tidak diterbitkan). Fakultas Ilmu Budaya, Universitas Andalas Padang.

Sudjianto dan Dahidi, Ahmad. 2009. Pengantar Linguistik Bahasa Jepang: Jakarta. Kesaint Blanc.

Ohkubo, Kanako. 2009. 'The Function of Sonkeigo and Kenjougo: An Analysis of MC Discourse at Japanese Wedding Receptions". The Japanese Journal of Language in Society.Volume 12, No. 1 (hlm. 162-173).

Rahayu, Eli Triasih. 2014. "Comparison of Honorific Language in Javanese and Japanese Speech Community ". International Journal on Studies in English Language and Literature (IJSELL). Volume 2, Issue 7 (hlm. 140-146).

Trianto (Ed). 2011. Pengantar Penelitian Pendidikan bagi Pengembangan Profesi Pendidikan dan Tenaga Kependidikan. Jakarta: Kencana Prenada Media Group.

Wijana, I Dewa Putu. 1996. Dasar-dasar Pragmatik. Yogyakarta: Penerbit ANDI.

Yule, George. 1996. Pragmatics. New York: Oxford University Pres 